\title{
“Traduzir é preciso": reflexões sobre a tarefa do tradutor ${ }^{2}$
}

\author{
Angela Derlise Stübe Netto (NETTO, Angela Derlise Stübe) \\ Dra. em Lingüística Aplicada, Universidade de Campinas - UNICAMP, professora do \\ Programa de Pós-Graduação em Letras, Universidade de Passo Fundo - UPF/RS \\ adsnetto@hotmail.com
}

\section{Resumo}

Neste texto, pautados pela Análise de Discurso de orientação pecheutiana, pela Desconstrução e pelos Estudos da tradução, analisamos como sites que oferecem serviços de tradução interlingual representam, na materialidade lingüística, a tarefa do tradutor. Nas análises, percebemos que as representações sobre a tarefa do tradutor são sustentadas, nesse meio, mais por princípios mercadológicos, calcados em um senso comum sobre tradução, que se funda numa visão logocêntrica, e menos, propriamente, em representações que têm os estudos tradutológicos mais recentes.

Palavras-chave: tradução, autoria, discurso.

\begin{abstract}
This paper analyzes how the translator's task is represented linguistically on sites advertising interlingual translation services on the internet. The theoretical framework is based on Discourse Analysis according to Pêcheux, Deconstruction, and Translation Studies. It was found that representations of the translator's task in this virtual medium are mostly nourished by market principles, which are influenced to a greater extent by a commonsense approach to translating, based on a logocentric view, and lesser by the conceptual background provided by recent translation studies.
\end{abstract}

Keywords: translation, author(ship), discourse.

\footnotetext{
${ }^{1}$ Expressão baseada em título de um poema de Fernando Pessoa, "Navegar é preciso”.

${ }^{2}$ Este texto é fruto da Qualificação em Área Complementar (Tradução), exigência do Programa de Doutorado em Lingüística Aplicada, IEL-UNICAMP, sob orientação da prof ${ }^{\mathrm{a}} \operatorname{Dr}^{\mathrm{a}}$ Carmen Zink Bolognini.
} 


\section{Introdução}

traduzir é ainda uma maneira de girar em torno do mistério, de suportar, de trabalhar o insuportável através de um termo-a-termo que produz sentido, 'jouis-sens'. Sabe-se muito bem que o ofício de tradutor se sustenta de uma impossibilidade inerente. Jamais se pode traduzir todo o sentido, mas tenta-se, frase por frase $[\ldots] .^{3}$

Este texto estabelece um contato entre a Análise de Discurso de orientação pecheutiana (doravante $\mathrm{AD}$ ) e os estudos da tradução ao refletir sobre a tarefa do tradutor. Para proceder a tal estudo, pretendemos empreender reflexões sobre a figura do tradutor, a partir da análise de sites que apresentam propagandas de sujeitos que trabalham com tradução e oferecem serviços de tradução interlingual. Observamos, nesses sites que serviram de corpora, as imagens de tradução através do modo como era descrita, ainda que de forma subjacente, na materialidade lingüística, a tarefa do tradutor. Vale ressaltar que nós não trabalhamos com a tradução intralingual ${ }^{4}$, apenas com a perspectiva de tradução interlingual oferecida por esses sites, para entendermos como são vistos os tradutores nesse meio midiático da internet, através de propagandas de serviços de tradução.

A escolha desse tema e desse corpus é pertinente porque, hoje, a internet é um dos meios midiáticos de maior circulação de informações e de maior agilidade ${ }^{5}$ no acesso aos serviços. Além disso, consideramos que as representações sobre tradução que emergem nos sites são constituídas por um imaginário que circula socialmente. Partimos do pressuposto de que as representações sobre a tarefa do tradutor - por consequência, sobre a tradução e sobre a figura do tradutor - são sustentadas, nesse meio, mais por princípios mercadológicos, calcados em um senso comum sobre tradução, que se funda numa visão logocêntrica, e menos, propriamente, em representações que têm os estudos tradutológicos mais recentes. Esses discursos atravessam, de alguma maneira, o imaginário do profissional da tradução e permitem que ele apresente sua tarefa de maneira $\mathrm{x}$ ou $\mathrm{y}$.

Em um universo amplo, como o da web, selecionamos aleatoriamente 12 sites para compor nosso corpus. Em pesquisa realizada em sites de busca, localizamos mais de 200.000 endereços que se referem, de forma mais ou menos direta, à tradução. Entretanto, estudamos o corpus de forma exaustiva em relação aos objetivos e à temática de análise e não em relação ao material lingüístico empírico. Isso devido à impossibilidade de realizarmos um estudo horizontal, já que buscamos uma exaustividade vertical (de profundidade na análise). Não buscamos a exaustividade horizontal (de abrangência), pois o discurso não se constitui linearmente; ao contrário, ele se constrói sobre discursos anteriores, formando uma rede, uma trama. O que se analisa aqui é o processo discursivo.

\footnotetext{
${ }^{3}$ Juta Prasse.

${ }^{4}$ Tradução intralingual (ou rewording) - atividade que todo sujeito efetua na sua tarefa de interpretar. "Consiste na interpretação de signos verbais por meio de outros signos da mesma língua" (JAKOBSON, 2003, p. 64).

${ }^{5}$ Essa questão da agilidade também aparece de modo incisivo e recorrente no corpus, conforme veremos no item 3 , correspondente à análise dos dados.
} 
Para isso, depois de breves considerações sobre teorias da tradução, que sustentam as análises, passamos a apresentar os principais resultados da análise dos sites de tradução selecionados.

\title{
Teorias da tradução
}

Grande parte dos estudos da tradução gira em torno de duas questões centrais: $\mathrm{O}$ que é tradução? Qual o papel do tradutor no processo tradutório? Esses foram, também, os questionamentos que guiaram nossa leitura dos autores que serviram de suporte teórico para nosso estudo. Para fins didáticos, organizamos as reflexões sobre tradução em três grandes grupos, segundo suas bases epistemológicas: 1) perspectiva tradicional; 2) perspectiva contestadora; e 3) perspectiva discursiva ${ }^{6}$.

\section{Perspectiva tradicional}

\author{
Tradução é uma arte. Uma pintura que pinta \\ com outras cores nova cópia original, para que \\ outros olhos enxerguem a mesma cena. Às \\ vezes a tradução pega carona numa analogia \\ que a leve ao destino do original. É preciso \\ criatividade nesta atividade [.... ${ }^{7}$
}

Esse recorte, extraído de nosso corpus de pesquisa, ilustra, de maneira poética, uma concepção recorrente nas teorias da tradução: traduzir é permitir que, em outra língua, enxergue-se a mesma cena.

Muitas teorias sobre tradução centram-se na discussão da fidelidade ao texto original. Dentre elas, as teorias tradicionais da tradução (de cunho lingüístico) trabalham sob a hipótese da completude e da simetria entre as línguas, propõem, para isso, a metáfora do transporte de sentidos e de formas de uma língua para outra, reduzindo ao mínimo a intervenção do tradutor.

Tradicionalmente, concebe-se a tradução como a transmissão do mesmo sentido ou da mesma forma de um original para uma outra língua (vide NIDA, 1964; MOUNIN, 1976; LADMIRAL, 1987; THEODOR, 1983; CATFORD, 1965; NEWMARK, 1976). Nessa concepção teórica, “espera-se que uma tradução reproduza os valores do original em uma troca com equilíbrio, ou seja, que traga em uma segunda língua, equivalentes em sentido ou em forma dos presentes em uma primeira língua” (RODRIGUES, 2000, p. 91).

Um autor significativo nessa linha teórica - além dos acima citados, entre outros - é Roman Jakobson. Suas reflexões acerca da tradução sintetizam, em grandes linhas, as preocupações centrais de uma perspectiva de natureza lingüística.

Jakobson (2003) - no artigo “Aspectos lingüísticos da tradução” - opõe-se a Russel, quando este considera que, para compreender qualquer palavra, é preciso um conhecimento não-lingüístico do objeto a que ela se relaciona, sem isso não é possível estabelecer sentidos. Jakobson discorda dessa tese. Para ele, o significado não está no

\footnotetext{
${ }^{6}$ Divisão tripartite e nomenclatura adotada a partir do livro de Mittman, "Notas do tradutor e processo tradutório”.

${ }^{7}$ Disponível em: www.mariopersona.com.br .
} 
objeto, mas no signo, o significado das palavras é um fato estritamente lingüístico. Essa visão de significação tem conseqüências para sua teoria da tradução. Dois pontos nos chamam a atenção: a centralidade do significado lingüístico e a primazia da palavra. Nessa perspectiva, traduzir é transpor significados de um signo lingüístico por um outro signo que lhe pode ser substituto (JAKOBSON, 2003, p. 64). Essa é uma visão estritamente calcada na língua e que sustenta uma concepção de tradução pautada na equivalência e na fidelidade, visando a um mínimo de perdas.

O autor apresenta três tipos de tradução: intralingual ou reformulação; interlingual ou tradução propriamente dita; intersemiótica ou transmutação. Para ele, entretanto, "no nível da tradução intralingual, não há comumente equivalência completa entre as unidades do código, ao passo que as mensagens podem servir como interpretações adequadas das unidades de código ou mensagens estrangeiras” (JAKOBSON, 2003, p. 65).

O que se destaca nessa afirmação é a preocupação com a equivalência entre as línguas e a possibilidade (ainda que ilusória) de manutenção de um sentido do texto original, que poderia ser transmitido à outra língua com o mínimo de perdas possíveis. Nessa perspectiva teórica, a tarefa do tradutor é recodificar e transmitir mensagens equivalentes de uma língua a outra (não apenas palavras): “o tradutor recodifica e transmite uma mensagem recebida de outra fonte. Assim, a tradução envolve duas mensagens equivalentes em dois códigos diferentes” (JAKOBSON, 2003, p. 65).

Nessa visão essencialista de texto, a tarefa do tradutor seria transferir o significado supostamente inerente ao original para uma outra língua, sem nele interferir, ou seja, "transferir o conteúdo de um texto com os meios próprios de outra língua" (THEODOR, 1983, p. 21). Qualquer “interferência” seria considerada perda. Frente a isso, com base em Tytler (apud ARROJO, 2000), podemos listar três princípios básicos que definiriam a "boa" tradução:

1 - a tradução deve reproduzir em sua totalidade a idéia do texto original;

2 - o estilo da tradução deve ser o mesmo do original; e

3 - a tradução deve ter toda a fluência e a naturalidade do texto original.

Partindo de tais princípios, a tarefa do tradutor é produzir um texto o mais fiel possível ao original e ficar invisível no texto traduzido. Em uma proposição mais forte, o objetivo é a reprodução do original em outro código. "Admite-se a subjetividade do tradutor, mas esta é tomada como um empecilho para a tradução ideal” (MITTMANN, 2003, p. 22).

Todavia, até mesmo teóricos que têm como objetivo sistematizar a noção de fidelidade, não conseguem esconder a relação de forças desencadeada pela tradução. É com base nessa tensão que muitos estudiosos, mais recentemente, têm contestado a perspectiva tradicional de tradução.

\section{Perspectiva Contestadora}

Há grandes divergências entre as ditas perspectiva tradicional e perspectiva contestadora, principalmente no que concerne ao modo de considerar o tradutor e o sentido (idem). De mero instrumento de transporte de sentidos estáveis naquela, o tradutor passa a ser visto como produtor do texto da tradução nesta.

Como a fixidez e a estabilidade dos sentidos passam a ser questionadas, há também uma releitura da noção de fidelidade, a qual é compreendida como "expressão 
em língua de chegada de uma leitura feita em língua de partida por um determinado indivíduo, sob determinadas condições de recepção e de produção” (AUBERT, 1989, p. 115). Logo, a tarefa do tradutor não é mais transporte, mas leitura de uma determinada mensagem, e toda leitura traz marcas da história do leitor e de suas condições de produção.

Nesse sentido, o tradutor será fiel não ao texto original, mas àquilo que ele considera ser o texto original, a partir de sua leitura da obra, sempre produto daquilo que ele é, sente e pensa. O tradutor passa a ser visto como inserido em um contexto cultural, ideológico, político que não pode ser eliminado ou ignorado ao elaborar uma tradução (ARROJO, 2003; BERMAN, 1981).

Venuti (1995, 2002), por exemplo, propõe que o tradutor “se marque” de alguma forma no texto traduzido, faça interferências declaradas, motivadas politicamente. Isso porque ele parte do pressuposto de que, inevitavelmente, o tradutor irá aparecer em qualquer tradução. A invisibilidade é apenas uma ilusão. Dessa forma, "o tradutor tem um papel ativo e responsável sobre a tradução, que é um ato de transformação e de produção” (MITTMANN, 2003, p. 34).

\section{Perspectiva discursiva}

Atualmente, em estudos interdisciplinares - que buscam o entremeio em teorias da tradução, da análise de discurso, da desconstrução e da psicanálise -, a tarefa do tradutor têm sido repensada, pois a tradução não é mais vista apenas como tarefa lingüística, mas em sua relação com a história, com a ideologia e com sujeitos socialmente situados e heterogeneamente constituídos.

Essa perspectiva propõe uma abordagem menos ilusória da tradução. O que implica, em primeiro lugar, o tradutor "reconhecer seu papel essencialmente ativo de produtor de significados e de representante e intérprete do autor e dos textos que traduz. Além desse reconhecimento, é claro, cabe ao tradutor assumir a responsabilidade pela produção de significados que realiza e pela representação do autor a que se dedica” (ARROJO, 2003, p. 104).

O tradutor se inscreve no discurso como uma posição-sujeito, que se sustenta a partir da ilusão de autonomia e de unidade do discurso e de si próprio, enquanto sujeito. Essa ilusão busca assegurar a coerência e a completude de uma determinada representação, necessária à constituição do sujeito e do discurso. Nesse sentido, podemos considerar que a ideologia atua internamente no processo tradutório, "criando no e pelo discurso os efeitos de evidência, universalidade e individualidade" (MITTMANN, 2003, p. 172).

Nesse contexto, ao falarmos do processo tradutório como construção de sentidos, estamos também apontando para a noção de interdiscurso (memória que sustenta todo dizer), noção fundamental, pois "é o interdiscurso que determina a FD [formação discursiva] à qual o indivíduo se vê interpelado” (MITTMANN, 2003, p. 174). Pêcheux nomeia o interdiscurso o "todo complexo com dominante das formações discursivas" (1988, p. 162), que geram a interpelação do sujeito. O "todo complexo" remete à memória discursiva e ideológica, que se encontra presente na construção de um discurso e evidencia as contradições existentes nas formações sociais. Essa memória discursiva concerne à existência histórica do enunciado no seio de práticas discursivas.

No que diz respeito a uma relação específica com o estudo desse texto, tais concepções teóricas nos permitem compreender a tradução como um gesto de interpretação realizado por um sujeito que ocupa o lugar social de tradutor. Vale aqui 
ressaltar que Pêcheux e Fuchs (1993) alertam para o fato de que lugar não pode ser entendido como espaço físico, não é algo da natureza objetiva, mas deve ser compreendido enquanto espaço de representações sociais. O lugar se representa, no funcionamento discursivo, através de um imaginário que designa o papel que o sujeito atribui a si e ao outro.

Compreender a tradução como interpretação consiste em considerar que o sujeito-tradutor busca sentidos, não os atribui. Dessa maneira é que podemos afirmar que o sentido é do sujeito e que a interpretação vai colocar em relação o campo da língua (lingüística) e o campo da sociedade (história e ideologia, que remetem o discurso à sua exterioridade).

Essa perspectiva teórica permite também discutir que, em tradução/interpretação, "nada é definitivo, sempre há espaço para a resistência, o deslizamento, a fuga, o equívoco, os outros sentidos” (MITTMANN, 2003, p. 177). Frente a essa postura, compreendemos a tradução como "um jogo, um gesto de desfazer o pano, desvelar a sua tessitura” (DERRIDA, 1997, p. 7). É também "pôr as mãos no objeto, puxando sempre novos fios" e acrescentando novos fios, "acrescentar não é aqui senão dar a ler” (DERRIDA, 1997, p. 7). É, “no mesmo tecido, nos mesmos textos”, puxar "outros fios, e de novo os mesmos, para aí urdirem-se ou desatarem-se novos desenhos” (DERRIDA, 1997, p. 29).

Vale ressaltar que, nessas três perspectivas teóricas, busca-se "firmar, ancorar os estudos da tradução, consolidando-os institucionalmente, e, sem essa consolidação, dificilmente poderá o teórico da tradução consagrar o melhor de seus esforços à reconstrução das pontes entre teoria e prática” (BENEDETTI, SOBRAL, 2003, p. 12).

\section{“Navegando” na tradução: análise de recortes discursivos}

A análise dos recortes discursivos abaixo se guiará a partir de uma questão central: o que significa ser tradutor nos sites analisados? Como resposta a essa pergunta, inúmeros sentidos emergem, evidenciando a pluralidade da linguagem, e alguns deles serão discutidos a seguir.

Ao explicar o processo tradutório, um determinado site apresenta, como recurso de persuasão do futuro cliente, um comentário sobre uma obra que traduziram. Tal comentário aponta, de forma interessante para uma concepção sobre a tarefa e a identidade de tradutor:

"É que esta escrita sustanciosa e aromática é para ser saboreada receita a receita, a qualquer hora do dia. E nosso foi o prazer de a traduzir, de a servirmos em primeira mão com o aroma da língua portuguesa. Mas como qualquer empregado de mesa, é agora o momento de nos retirarmos em silêncio e deixarmos que sejam os comensais a empreender a descoberta da textura dos sentidos numa fruição preambular do Amor." ${ }^{8}$

O tradutor faz afirmações elogiosas sobre a obra e o sobre o prazer de traduzi-la, o que podemos ver na escolha de substantivos e adjetivos (por exemplo, "escrita substanciosa e aromática”). Traduzir, aqui, é se envolver com a obra, deliciar-se com ela, "mas como qualquer empregado de mesa". Ao tradutor cabe colocar-se a serviço do

\footnotetext{
${ }^{8}$ Doravante, todos os recortes extraídos do corpus de pesquisa serão destacados no texto através de itálico e aspas.
} 
autor (e da obra), para que o público de outra língua também possa saboreá-la, a ele cabe "servir[-la] em primeira mão com o aroma da língua portuguesa". A primazia permanece no original, é ele quem deve ser visível, ao tradutor resta "retirar[-se] em silêncio".

Esses possíveis sentidos denunciam que há uma centralidade do “original” e uma rejeição do 'imitado' em nossa cultura. Essa rejeição produz efeitos nos sentidos que circulam na web (e na sociedade) sobre a tradução. Essa rejeição, por exemplo, pode ser notada quando nos deparamos com um livro traduzido, no qual o tradutor não é sequer citado. Essa prioridade do original aponta para a premência das noções de equivalência e de fidelidade, que ainda são muitos fortes nos sites que oferecem serviços de tradução. Entretanto, essa fidelidade é possível?

"E nós, tradutores, leitores privilegiados de primeira mão, fomos tentando verter, sem entornar, para a nossa língua, os segredos da mesa e da cama que uma senhora chilena resolveu partilhar com o mundo com a inocência da primeira descoberta."

Nesse recorte, podemos perceber que o sujeito considera os tradutores como leitores privilegiados da obra. Leitura aqui como possibilidade de verter sentidos de uma língua a outra. Com uma rápida visada no dicionário, buscamos possíveis sentidos para o ato de verter: "fazer transbordar, entornar, derramar; espalhar, difundir; traduzir, trasladar” (AURÉLIO, 1995, p. 1770). Na tradução, o texto pode transbordar sentidos, mover-se, difundir culturas. E esse movimento vai gerar efeitos nas duas línguas, tanto na de partida, quanto na de chegada. Parece evidente que não se pode exigir uma fidelidade àquilo que é por definição inacessível: o original.

Assumimos, então, que a tradução é formulada "a partir de uma amálgama de leituras, vicissitudes, interpretações, demandas, recriações, fantasias, angústias, gozos, letras, litorais, ilusões, desejos: tudo aquilo que faz do processo tradutório algo humano, demasiadamente humano” (BONATTI, 1999, p. 170). Todavia, o site não dá conta de toda essa complexidade, apenas aponta para ela, já que considera ser possível verter "sem entornar". Emerge novamente, no fio discursivo, uma memória sustentada pelo discurso logocêntrico da fidelidade ao original e da equivalência entre línguas. Disso podermos inferir que a idéia de equivalência mascara uma relação de poder, em que uma cultura procura impor-se sobre outra.

Compartilhamos a opinião de Siscar, quando afirma que as teorias de inspiração pós-moderna passam a "interpretar o apego à noção estável de original e aos diversos mecanismos de afirmação da 'equivalência' como uma estratégia ou, pelo menos, como uma herança idealista de nossa maneira de ver a linguagem e o mundo de maneira geral” (2001, p. 90). Nessas teorias, a tradução é compreendida como uma leitura de um texto sem significado intrínseco e/ou unívoco. Em vista disso, "se a leitura é sempre um ato de desvio, caracterizado por uma certa violência, não há serenidade possível diante da tradução (SISCAR, 2001, p. 90). A tradução é sempre um ato tenso, desvela conflitos entre línguas e identidades culturais, por isso "nós, tradutores" não podemos subsumir à tentação de acreditar na ilusão de que seja possível "verter, sem entornar”. O tradutor é, também, produtor de sentido e a tradução é o espaço "onde se deixam ler os traços ideológicos e pulsionais da constituição do texto” (SISCAR, 2001, p. 87).

A tradução é um acontecimento de linguagem. A noção de acontecimento instaura o ponto de encontro entre uma atualidade e uma memória (PÊCHEUX, 1997), ela se inscreve na e reescreve a memória discursiva, o que desloca a concepção de fidelidade na tarefa do tradutor. A partir daí, “o tradutor passa a ser um sujeito que 
intervém de maneira efetiva na transformação e produção de significados, por meio de uma espécie de implante, de contaminação entre as línguas envolvidas na tradução” (OTTONI, 2000, p. 46).

Entretanto, nem sempre são esses os sentidos que preponderam nos sites, o discurso do mercado, aliado à ilusão de fidelidade, são muito fortes, como vemos em um site cujo cabeçalho apresenta a pergunta "quem somos?” A resposta é dada pelo texto: aqueles capazes de "suprir a necessidade de clientes". A fidelidade não é apenas em relação ao texto original, mas também a uma exigência posta pelo mercado:

\begin{abstract}
"Para suprir a necessidade de clientes que atuam em um mercado transnacional [...] reuniu uma equipe de profissionais de diferentes nacionalidades e com formação superior em diversas áreas de conhecimento. Desta forma, é possível cobrir uma gama cada vez maior de segmentos e garantir que o texto elaborado no idioma final seja fidedigno não só no que diz respeito à utilização de termos específicos da área, mas também ao uso da linguagem e das estruturas apropriadas da língua. O trabalho de tradução, portanto, não consiste numa mera conversão de um idioma a outro, vai muito além, visto que deve adaptar o texto às estruturas e aos usos do idioma final sem que haja uma perda do tom e das características próprias do texto original."
\end{abstract}

O sujeito desse site enuncia, explicitamente, que "o trabalho de tradução, não consiste numa mera conversão de um idioma a outro, vai muito além". Em uma primeira impressão, parece inscrever seu discurso em concepções de teorias da tradução mais recentes, que buscam discutir e ampliar sua visão sobre o processo tradutório. No entanto, esse é apenas um jogo de sentidos utilizado como estratégia de persuasão de um cliente que busca novas perspectivas de tradução.

O que prevalece, todavia, é a tradução pensada como transporte de significados entre língua A e língua B, "sem que haja uma perda do tom e das características próprias do texto original"; o texto original - visto como um objeto estável, 'transportável', de contornos absolutamente claros - ainda é um ideal perseguido, no qual a "perda” (ou seria transformação?) ainda é um "mal” a ser evitado para "garantir que o texto elaborado no idioma final seja fidedigno" ao original. Novamente, emergem sentidos vinculados à tradução como transporte, translado. Se compararmos o tradutor ao encarregado do transporte dessa carga, "assumiremos que sua função, meramente mecânica, se restringe a garantir que a carga chegue intacta ao seu destino. Assim, o tradutor traduz, isto é, transporta a carga de significados, mas não deve interferir nela, não deve interpretá-la” (ARROJO, 2003, p. 102).

Salta aos olhos que, diferentemente dos teóricos citados nos itens 2.2 e 2.3, esses sites parecem defender uma visão tradicional e essencialista em relação à fidelidade e ao papel do tradutor. Johnson (1998), ao abordar a questão da fidelidade na tradução, considera que o tradutor deve ser "um bígamo fiel”, isto é, deve dividir a sua lealdade entre as duas línguas: a língua de partida e a língua de chegada. Esse paradoxo fidelidade/infidelidade, segundo a autora, tem origem nos trabalhos de Derrida. É no espaço da différance que Derrida pensa a significação e a tradução. Tal perspectiva traz implicações para a tarefa do tradutor:

o tradutor deve, apesar ou talvez por causa de seu juramento de fidelidade, ser considerado não um cônjuge cônscio de seu dever, mas um bígamo fiel, com lealdades divididas entre uma língua nativa e uma estrangeira. Cada uma deve 
acomodar as exigências da outra sem que as duas jamais tenham a oportunidade de se encontrar. (JOHNSON, 1998, p. 27, grifo meu)

Nessa citação, impera o vocabulário que aponta sentidos da dívida do tradutor deve. Dívida para com as línguas de chegada e de partida, para com o texto, para com o autor e para com o leitor. Esses efeitos de sentidos ecoam por muitos sites, colocando o tradutor em um lugar de dever, de obrigação, instando-o a ocupar um papel social que se assenta na necessidade e na impossibilidade da tradução (double bind). Esses efeitos, em relação à tradução, Derrida (2002, p. 25) já havia ressaltado, quando anuncia que “a tradução torna-se a lei, o dever e a dívida, mas dívida que não se pode mais quitar”. Há uma dívida insolúvel do tradutor; o sujeito da tradução é um sujeito endividado, obrigado por um dever.

Voltamos aos recortes e aos sentidos que deles podemos inferir. Para exercer sua tarefa, o tradutor precisa possuir certas características particulares. Dentre elas, ser proficiente na língua de partida e na língua de chegada, e tal proficiência é associada ao fato de ser nativo, além de ser especialista (ou dominar muito bem) a área específica do texto traduzido. Essas imagens são muito fortes e recorrentes nos sites analisados, inclusive como forma de venda do produto "tradução":

- “dispomos de tradutores especializados em diversos campos”;

- "os nossos tradutores, de expressão nativa, podem traduzir os seus documentos e web sites em mais de 40 línguas";

- "Contamos com em diversas áreas, tornando o trabalho final de altíssima qualidade e fidelidade ao original apresentado";

- "as equipes da ILanguage são formadas por tradutores nativos profissionais [...], tendo a certeza de que eles não são proficientes apenas no idioma de chegada, mas também em suas áreas de especialização.”

Essas características deveriam propiciar ao profissional uma valorização de sua atividade, já que são "profissionais nativos experientes”, “especializados”, tanto quanto uma revalorização do texto traduzido. Entretanto, apesar dessa pretensa valorização, lado-a-lado permanecem os discursos que conferem um caráter secundário e de simulacro ao texto traduzido - "trabalho final de altíssima qualidade e fidelidade ao original apresentado". Muitas teorias recentes colocam-se como desafio resgatar o interesse e a importância do texto traduzido, para "restaurar a dignidade do excluído, do reprimido, daquilo que é sistematicamente marginalizado como derivação do original" (SISCAR, 2001, p. 87). Isso será possível, apenas, quando o tradutor assumir o lugar de senhor do processo criativo na sua língua.

Ele - tal como o autor - é instado, por uma contingência, a possuir uma escrita singular, que consiga compartilhar na sua língua materna a mesma ousadia do autor. Por exemplo, um determinado site apresenta a seguinte imagem de seu profissional da tradução: ele "é dono de uma habilidade natural de contar histórias e fazer analogias, sabe criar uma imagem simples de coisas complexas e transformar algo indigesto em algo apetitoso" (grifo do site). Toda a mídia do site centra-se na afirmação de que "Seu texto será traduzido por um escritor."

Isso é possível, porque o sujeito possui “uma habilidade natural” para contar histórias, comunicar-se por escrito, ele "sabe criar uma mensagem simples de coisas complexas e transformar o indigesto em algo apetitoso". O recorte é permeado por um vocabulário (e sustentado por um discurso midiático) que pretende seduzir o leitor, levá- 
lo a "degustar" a mensagem do site e escolhê-lo como melhor opção de compra (como opções oferecidas em um menu).

Essa possibilidade de "transformar o indigesto em algo apetitoso" é permitida por três características básicas do tradutor (e que constituem sua tarefa): dominar a língua de partida e de chegada; ter excelente domínio do conteúdo, já que sabe "criar uma mensagem simples de coisas complexas"; e ser um bom escritor, saber ousar, tal como é permitido ao autor. E essa ousadia requer liberdade para assumir seu papel no processo criativo.

A importância grande dada ao domínio do conteúdo específico da área, como garantia de um "bom" trabalho tradutório - com a ilusão de "segurança total" também é evidenciada no recorte a seguir:

"Tradução de manuais técnicos (inglês/português) englobando:

- Fluxogramas

- Organogramas

- Imagens

- Softwares

Nossos profissionais são formados nas áreas de Tecnologia e Informática, garantindo uma segurança total das informações de seu manual."

Todas essas características o tradutor precisa possuir para realizar sua tarefa, de forma a tornar a tradução um produto passível de venda. Várias chamadas dos sites jogam com os sentidos de preços baixos, agilidade na execução da tarefa, confiabilidade no trabalho tradutório, fidelidade, como tarefas do tradutor que garantam a parceria com o cliente e a satisfação com a tradução. Esse "discurso do consumo" também se marca insistentemente no corpus e gera efeitos no imaginário sobre o trabalho da tradução:

- “Aqui você encontrará a solução para os serviços de traduções nas áreas de Tecnologia e Informática, com ótima qualidade e o preço mais baixo do mercado";

- "reduções de custo, satisfação do cliente";

- "traduções com rapidez e confiabilidade";

- "qualidade elevada com baixo custo";

- "comercialização mais rápida, com excelente execução do projeto dentro do prazo".

Tudo isso sustenta uma visão de tradução como uma tarefa secundária, submissa a um texto poderoso e a um autor dono de um dizer. Passa-se a imagem para o público, através dos sites, de uma onipotência que pudesse produzir uma tradução livre de qualquer erro e que estivesse imune a qualquer mudança de contexto. Essa visão tradicional deixa explícita a mensagem de que um "original” é resultado da criatividade de seu autor e o texto traduzido é sempre mera reprodução.

Entretanto, emergem no discurso outros sentidos, que apontam outras configurações sobre a tarefa (e identidade) do tradutor e consideram que ele "assina solidário com o autor e empresta sua reputação à peça”. Ao assinar (mesmo que seja de forma solidária), o tradutor imprime a sua marca na obra.

"Neste sentido, constituímos um caso algo diferente, pois o nosso trabalho de tradução é feito integralmente em equipa [sic], conjugando duas formações separadas, duas formas de sentir individuais que no entanto se interligam na elaboração do texto traduzido. Amor e arte misturam-se para dar lugar a um 
processo criativo mais enriquecedor, pois é disso que se trata fundamentalmente: de um processo criativo, que não se sobrepondo ao do autor é também criador de cultura."

Realmente, no universo dos sites pesquisados, este constitui "um caso algo diferente". Destacamos o termo "algo", pois não foge totalmente ao senso comum. Muitos sites dizem que fazem trabalhos em equipe. Este se diferencia por, explicitamente, abordar as diferenças culturais e a tradução como criação de cultura, através do contato entre duas línguas e duas culturas diferentes. Traduzir é sempre jogar com culturas, com formações sociais.

Do que é exatamente responsável o tradutor quando a questão de sua tarefa se coloca nos sites? Como vimos, alguns efeitos de sentido se constituem: ele é responsável por ser amigo do cliente, ser fiel ao texto original, ser ágil em cumprir sua "tarefa” no menor prazo e pelo menor custo, ser proficiente na língua de partida e na língua de chegada, além de ser profundo conhecedor do assunto a ser traduzido, transmitir a mensagem de forma clara e bem escrita, criar um universo cultural, entre outros (já que os sentidos deslocam-se, migram, transformam-se). Resta, por fim, a questão: frente a essas representações, que tipo de produção de sentidos é possível quando o imperativo da tradução torna-se, sistematicamente, o mercado e o cliente?

Observamos, pela análise, que os sujeitos no corpus são instados a se identificar com a formação discursiva (FD) que os domina - aquela que sustenta discursos ligados a relações mercadológicas (de consumo), pautadas em uma concepção essencialista de sentido e de sujeitos. Todavia, a FD está em contínuo movimento, reconfigurando o seu domínio de saber e desestabilizando as suas fronteiras, pois é constituída pela heterogeneidade, impulsionada pelo movimento contraditório entre o único e o disperso (COURTINE, 1981). Nesse movimento de desestabilização, ocorrem atravessamentos, constituindo o discurso de forma heterogênea. O sujeito intervém no repetível de tal forma que gera o diferente, permitindo a emergência de outros discursos, como, por exemplo, de que o tradutor "é também criador de cultura".

Nesse movimento, a tradução faz trabalhar o saber da/na língua (tanto de partida como de chegada), permitindo emergir sempre novas significações. Este trabalho é agenciado pela permeabilidade das línguas, em outras palavras, aquilo que elas deixam passar entre si. Ninguém sai incólume do processo tradutório: nem línguas, nem sujeitos. A tradução, tem por tarefa desvelar o

embate reconhecidamente dos mais árduos, no fogo cruzado do difícil (o limite, do impossível) diálogo de duas línguas, duas culturas, dois tempos, dois espaços, duas visões de mundo, duas condições de produção, intrinsecamente não redutíveis um ao outro exceto por uma conciliação que, muitas vezes, pode tomar feições de uma violentação ou de uma apagamento da alteridade. (BENEDETTI; SOBRAL, 2003, p. 10)

\section{(In)conclusões}

A partir das análises, pudemos perceber que as representações sobre a tarefa do tradutor são sustentadas, nos sites, mais por princípios mercadológicos, calcados em um senso comum sobre tradução, e menos, propriamente, em representações que têm especialistas e teóricos da tradução. Esses discursos atravessam, de alguma maneira, o 
imaginário do profissional da tradução e permitem que ele apresente sua tarefa como: fidelidade, agilidade, compromisso com interesses do mercado, criação cultural.

Enquanto os trabalhos teóricos de diferentes vertentes atuais se distanciam de uma perspectiva tradicional, de cunho essencialista e logocêntrico, as representações sobre a tarefa do tradutor, que perpassam os sites analisados, evidenciam, em muitos momentos, uma visão já considerada ultrapassada por parte dos teóricos.

Consideramos que esse senso comum é calcado em uma concepção logocêntrica, arraigada na nossa forma de ver e compreender o mundo e as relações nele implicadas. A visão que prevalece é uma visão lingüística e não baseada em estudos mais recentes na área, que abarcam o social, o ideológico e o sujeito desejante. Isso talvez ocorra porque tais estudos ainda não conseguiram sair da academia e avançar nos meios em que a tradução circula cotidianamente. Benedetti e Sobral (2003) já apontam que há discrepância entre o volume do trabalho teórico produzido e a parcela desse trabalho efetivamente divulgado.

Concebemos que a tarefa do tradutor é uma tarefa sem fim, porque a tradução ideal jamais é alcançada. A “própria atividade tradutória tem o estatuto de provisoriedade, restando sempre a alternativa de ser refeita, ainda que para efeito de contemporaneidade” (BONATTI, 1999, p. 6). Dessa forma, na Desconstrução, o original ganha outro estatuto e a idéia de equivalência passa a ser questionada nas suas bases.

Para proceder a tal deslocamento, Derrida (2002) propõe que refletir sobre o mito de Babel e a impossibilidade de transparência significa refletir sobre a tradução. No movimento de sentidos gerado pelo mito da Torre de Babel, destaca-se que Deus instituiu a diversidade de línguas e, com isso, destina e sujeita os Shem à tradução, à “tarefa necessária e impossível da tradução” (DERRIDA, 2002, p. 21). Isso porque

a dispersão das línguas instaurada no mito condena o homem à necessidade de tradução, mas também a um trabalho que nunca estará completo, porque a tradução perfeita, a transparência, só seria possível com a imposição de uma língua universal como queriam os Shem. Com esse relato, Derrida mostra como Deus, ao mesmo tempo que dá o presente da heterogeneidade, da diversidade das línguas, oferece o veneno da impossibilidade de redução a um igual; torna necessária a tradução e marca a impossibilidade da transparência. Em lugar da compreensão universal almejada pelos Shem, institui-se a multiplicidade de línguas e o reino da diferença. (RODRIGUES, 2000, p. 90)

Ao analisar o mito da Torre de Babel, Rodrigues considera que a dispersão das tribos e a multiplicidade das línguas, daí decorrente, instaura a diferença e a desigualdade entre línguas, culturas, valores, grupos sociais, não promove o intercâmbio e nem o equilíbrio entre as línguas. Assim, "é problemático encarar a tradução como uma relação de equivalência, na medida em que pratica a diferença entre valores, crenças, representações sociais e funciona como agente de domínio.” (RODRIGUES, 2000, p. 89)

Nessa perspectiva, a noção de equivalência (que pressupõe unidade e homogeneidade) passa a ser questionada. Ela não tem espaço nesse reino de différance. Da mesma forma, a noção de original é deslocada. No movimento da différance, o original precisa ser compreendido no trabalho da alteridade, inscrito em qualquer prática discursiva. Isso porquê não há 
sentido original antes de uma leitura. Aquilo que chamamos original se estabelece e se modula segundo as diversas interpretações de um texto que, dessa maneira, perde qualquer essência ou significados intrínsecos. O sentido do original é o sentido que lhe atribui um leitor ou uma determinada situação interpretativa, um determinado contexto de leitura. [...] Não existe original antes de sua tradução; é a tradução que, de alguma maneira, cria seu original”. (SISCAR, 2001, p. 87)

O original depende de novas leituras, não na ilusão logocêntrica de resgatar e sustentar um sentido primeiro e estável. Cada nova leitura do texto é uma leitura original, no sentido de originar/produzir novos efeitos de sentidos e deixar rastros, marcas (spuren) nas leituras possíveis (sócio-historicamente legitimadas) do texto. Nesse sentido, a seguinte citação de Derrida nos parece reveladora:

Um texto só é um texto se ele oculta ao primeiro olhar, ao primeiro encontro, a lei de sua composição e a regra de seu jogo. [...] A dissimulação da textura pode, em todo o caso, levar séculos para desfazer o pano. O pano envolvendo o pano. Reconstituindo-o, também, como um organismo. Regenerando indefinidamente seu próprio tecido por detrás do rastro cortante, a decisão de cada leitura. (1997, p. 7)

Traduzir é, então, “acreditar dominar o jogo”, acreditar nessa ilusão. Mas é mais... é "pôr as mãos no objeto”, é “dar a ler” (DERRIDA, 1997, p. 7).

A reflexão desencadeada por esses autores desafia a noção de tarefa do tradutor como propiciar equivalência entre um texto original e um texto de chegada (questiona inclusive as noções de original e de texto de chegada). A tarefa do tradutor, sob essa perspectiva (que não se evidencia no corpus em análise), é "ministrar" o remédioveneno, é entrar no jogo do pharmakon, assumir os riscos da Babel. Assumir tais riscos implica uma atitude ativa do tradutor, sua tarefa deixa de ser transposição de uma língua a outra, passa a um caráter autoral.

\section{Referências}

AUBERT, Francis. A fidelidade no processo e no produto do traduzir. Trabalhos de Lingüística Aplicada, n. 14, p. 115-119, jul./dez., 1989.

ARROJO, Rosemary. (Org.). O signo desconstruído: implicações para a tradução, a leitura e o ensino. Campinas: Pontes, 2003.

BENEDETTI, Ivone; SOBRAL, Adail. Conversas com tradutores: balanços e perspectivas da tradução. São Paulo: Parábola, 2003.

BERMAN, Antoine. A prova do estrangeiro. Bauru, SP: EDUSC, 1981.

BONATTI, Nícia. Entre o amor da língua e o desejo: a tarefa sem fim do tradutor. 1999. Tese (Doutorado em Lingüística Aplicada) - Instituto de Estudos da Linguagem, Universidade Estadual de Campinas. Campina, 1999. 
CATFORD, J. Uma teoria lingüística da tradução. São Paulo: Cultrix, PUCCAMP, 1965.

DERRIDA, Jacques. A farmácia de Platão. São Paulo: Iluminuras, 1997.

Carta a um amigo japonês. In: OTTONI, P. (Org.). Tradução: a prática da diferença. Campinas (SP): UNICAMP, 1996. p. 19-25.

Torres de Babel. Belo Horizonte, MG: UFMG, 2002.

JAKOBSON, Roman. Aspectos lingüísticos da tradução. In: Lingüística e comunicação. 19. ed. São Paulo: Cultrix, 2003, p. 63-72.

JOHNSON, Bárbara. A fidelidade considerada filosoficamente. In: OTTONI, P. (Org.). Tradução: a prática da diferença. Campinas: UNICAMP, 1998.

LADMIRAL, Jean René. Theoremes pour la traduction. Cahiers du departement des langues et des sciences du langage, Universite de Lousanne, n. 5, p. 3-17, 1987.

MITTMANN, Solange. Notas do tradutor e processo tradutório. Análise e reflexão sob uma perspectiva discursiva. Porto Alegre: UFRGS, 2003.

MOUNIN, George. Linguistique et traduction. Bruxelles: Dessart et Mardaga Editeurs, 1976.

NEWMARK, Peter. The theory and the craft of translation. Language Teaching and Linguistic Abstract, p. 79-100, jan. 1976.

OTTONI, Paulo. A tradução da différance: dupla tradução e doublé bind. Alfa: Revista de Lingüística, n. 44 (esp), p. 45-58, 2000.

PÊCHEUX, Michel. Análise automática do discurso. In: GADET, Françoise; HAK, T. (Orgs.). Por uma análise automática do discurso: uma introdução à obra de Michel Pêcheux. 2. ed. Campinas: UNICAMP, 1993. p. 61-162.

PÊCHEUX, Michel. Semântica e discurso. Uma crítica à afirmação do óbvio. Campinas: UNICAMP, 1988.

PÊCHEUX, Michel. O discurso. Estrutura ou acontecimento. Campinas: Pontes, 1997.

RODRIGUES, Cristina Carneiro. Tradução: a questão a equivalência. ALF: Revista de Lingüística, São Paulo: UNESP, v. 44, n. esp., p. 89-98, 2000.

SISCAR, Marcos. A dificuldade de origem. Revista Letras, Curitiba, Pr: UFPr, n. 56, p. 85-93, jul/dez. 2001.

THEODOR, Erwin. Tradução: ofício e arte. São Paulo: Cultrix, USP, 1983. 
VENUTI, Lawrence. A invisibilidade do tradutor. Palavra, PUC-Rio, v. 3, p. 11-134, 1995.

VENUTI, Lawrence. Escândalos da tradução: por uma ética da diferença. Bauru, SP: EDUSC, 2002.

\section{SITES que compuseram o corpus de pesquisa}

http://www.sbb.org.br

http://www.terravista.pt/aguaalto/1105

http://www.planeta.terra.com.br/servicos/tramatec/index.htm

http://www.mariopersona.com.br

http://www.casadostradutores.com.br

http://www.ilanguage,com.br

http://www.adl.com.br

http://www.oliberal.com.br/traducao

http://babylon.terra.com.br

http://www.wordlingo.com.pt

http://www.jecnet.com.br 